\title{
Scratch Jr - Brincando em Família: um relato de experiências sobre introdução a programação no ambiente escolar
}

\author{
André Luiz Maciel Santana1, André Luís Alice Raabe ${ }^{123}$, Julia P. Metzger1, \\ Alisson S. Henrique ${ }^{1}$, Luís F. M. Santana ${ }^{14}$, Annelize da C. P. Maciel ${ }^{15}$, Clara \\ Maciel $^{6}$ \\ ${ }^{1}$ Laboratório de Inovação Tecnológica na Educação - CTTMar - UNIVALI \\ ${ }^{2}$ Programa de Pós-Graduação em Educação \\ ${ }^{3}$ Mestrado em Computação Aplicada \\ ${ }^{4}$ Curso de Arquitetura e Urbanismo \\ ${ }^{5}$ Curso de Nutrição \\ ${ }^{6}$ C.E.I. Prof ${ }^{a}$ Rosana Aparecida de Souza - (Município de Itajaí) \\ andrelms@univali.br, raabe@univali.br, lite@univali.br
}

\begin{abstract}
This paper shows the main results of an experience report about the introduction to programming with 19 children of 5 years old and their families. That methodology has approximated the family and school, using Scratch Jr such as technology to promote a different school-family day. The results indicate that it is possible to introduce programming concepts in kindergarten and the most positive points are: (i) building alternatives to explore creative and inventive potential with children and (ii) indicating the methodology to replicate that experience in other public schools in Brazil.
\end{abstract}

Resumo. Este artigo apresenta os principais resultados de um relato de experiência sobre introdução a programação com 19 crianças de 5 anos de idade e seus familiares. As atividades permitiram integrar a família e a escola, por meio do uso da tecnologia Scratch $\mathrm{Jr}$ em um dia diferente de atividades no espaço escolar. Os resultados indicam que é possível introduzir conceitos de programação na educação infantil e que os principais aspectos positivos da metodologia especificada estão relacionados a viabilizar mais uma alternativa para as crianças explorarem seu potencial criativo e inventivo. Como principal contribuição, este trabalho apresenta uma estratégia para replicação deste experimento em outros espaços escolares e os artefatos utilizados.

\section{Introdução}

A diversão e as brincadeiras em turma são parte das principais atividades presentes na educação infantil brasileira, enquanto se divertem, as crianças aprendem conceitos presentes no letramento e matemática, a resolver os seus primeiros conflitos sociais e a conquistar novas experiências. Nesta mesma fase da vida, as crianças são estimuladas quanto a criatividade e recebem as primeiras influências fora do ambiente familiar, através de seus educadores e da própria escola (RAABE et al. 2015)

Resnick (2007) apresenta que uma das principais dificuldades para que o ser humano vença seus desafios na vida adulta, estão relacionados a redução de sua 
capacidade criativa ao longo dos anos de sua vida, e que de alguma forma a essência vivenciada durante a educação infantil, vai se perdendo. Como estratégia para potencializar a criatividade, o autor sugere uma abordagem baseada nos 4 P's: project, pers, passion and play, que respectivamente tratam de criar um projeto que seja compartilhável com outras pessoas, experimentando-o e que acima de tudo, trate da paixão do desenvolvedor pelo seu projeto

A ferramenta Scratch Jr (PORTELANCE; STRAWHACKER; BERS, 2015) (PORTELANCE; BERS, 2015) foi desenvolvida a partir do Scratch e conta com uma série de recursos que viabilizam que crianças ainda não alfabetizadas e que estejam na educação infantil, sejam capazes de criar suas primeiras histórias programáveis. Segundo Flannery et al. (2013), a ferramenta foi concebida a partir da necessidade de alternativas para ensino de programação com crianças que estivessem ainda no jardim de infância, priorizando o desenvolvimento de habilidades de resolução de problemas, letramento, matemática e reforçando habilidades cognitivas e sociais.

Portelancer, Strawhacker e Bers (2015), apresentaram que é possível integrar atividades de introdução a programação no ambiente escolar, de forma a explorar a criatividade das crianças e ao mesmo tempo contribuir para sua formação. Em suas pesquisas, os autores se basearam no currículo STEM (Science, Technology, Engineering and Math) e identificaram que o Scratch $\mathrm{Jr}$ contribui para o desenvolvimento de habilidades cognitivas, emocionais, pessoais e sociais. Além disso, este tipo de pesquisa já vêm sendo abordados em na educação infantil com outras estratégias, que igualmente valorizam o protagonismo das crianças (TEIXEIRA et al, 2015; PAPADAKIS, KALOGIANNAKIS e ZARANIS, 2016)

Este relato de experiência tem por objetivo apresentar os principais resultados de uma atividade realizada na cidade de Itajaí pelo LITE - UNIVALI, que utilizou o Scratch Jr para introduzir conceitos de programação por meio de uma abordagem de aprendizagem criativa. Nesta atividade, foram envolvidos educadores, os pais/responsáveis pelas crianças e uma turma da educação infantil, composta por crianças de 5 anos de idade.

\section{Metodologia de Aplicação}

O Scratch Junior: uma brincadeira em família é um evento de um dia com duração de 130 minutos e que proporciona uma interação entre crianças e seus familiares com o objetivo de juntos criarem histórias e animações. No processo de criação, as crianças são estimuladas a se expressarem quanto sua criatividade, gostos pessoais e vivências em família por meio da programação.

Para a participação do evento sugere-se um sistema de inscrições das famílias participantes, uma vez que é necessário viabilizar todos os recursos apresentados na seção 2.3 e que são importantes para a aplicação das atividades.

\subsection{Protocolo Execução}

O protocolo de execução desta atividade é uma modificação do protocolo original desenvolvido pela Universidade de Tufts (criadora da ferramenta Scratch Jr). Após a aplicação das atividades com o protocolo original, foi percebida a necessidade de algumas alterações para que se pudesse estimular ainda mais a Aprendizagem 
VI Congresso Brasileiro de Informática na Educação (CBIE 2017)

Anais do XXIII Workshop de Informática na Escola (WIE 2017)

Criativa, por meio de estratégias que envolvem computação, mão na massa e o próprio ambiente escolar.

O protocolo de execução adaptado pelo Lite, tem duração de 130 minutos e é dividido em 6 (seis) etapas diferentes e uma introdução que deve ocorrer antes do início do evento: (intro) atividade mão-na-massa (que não existia no protocolo original); (i) recepção das famílias e entrega dos materiais; (ii) estímulo de criatividade para as crianças e apresentação da ferramenta aos familiares (adaptado do protocolo original); (iii) codificação em conjunto; (iv) troca de experiências; (v) refatoração das animações e histórias; e (vi) apresentação dos trabalhos. Para desenvolver estas seis etapas do protocolo, sugere-se a participação de pelo menos quatro instrutores e um professor/educador com vínculo afetivo com as crianças.

Inicialmente, sugere-se como atividade de introdução, uma interação entre os educadores envolvidos e a equipe de pesquisadores. Nestas atividades que precedem o evento, são esclarecidos aos educadores que o objetivo é de estimular a aprendizagem de conceitos presentes na computação, mas priorizando a capacidade criativa das crianças, sugerindo deste modo, que elas não sejam inibidas de pensar da forma como desejam. Ainda neste contexto, as crianças são convidadas a criarem crachás de identificação com desenhos de como imaginam os personagens presentes no Scratch Jr, estas atividades ocorrem alguns dias antes do evento e fortalecem o vínculo entre escola-criança-família, uma vez que estes crachás serão utilizados pelos pais/responsáveis durante todo evento para identificação.

A primeira etapa consiste em uma apresentação do evento e uma descrição geral sobre o cronograma do dia. Nesta etapa os familiares recebem os tablets, os crachás criados por seus filhos na etapa de introdução e são esclarecidos sobre eventuais dúvidas, como duração do evento.

A segunda etapa do protocolo sugere a divisão entre crianças e os seus familiares em dois grupos distintos. Em um grupo os pais/responsáveis realizam em que aprendem sobre conceitos do uso da ferramenta Scratch Jr, com um introdução sobre as principais funcionalidades do programa. Enquanto no outro grupo as crianças são apresentadas para alguns exemplos de animações criadas no Scratch Jr, a uma conversa informal sobre o que elas gostariam de criar e a atividades que envolvem pintura de personagens e desenhos de como imaginam que podem ser seus cenários e/ou histórias.

As atividades realizadas com os familiares são desenvolvidas com o apoio de um documento guia, que foi traduzido para o português para viabilizar a compreensão das funcionalidades básicas da ferramenta por famílias brasileiras. Este documento pode ser encontrado em <https://goo.gl/5ooGRH>. Além disso, nesta segunda etapa, as crianças são instigadas a pensar como é possível fazer com que desenhos se mexam utilizando programação. Esta etapa dura cerca de 30 minutos.

Para a terceira etapa as crianças e os familiares se unem em um mesmo local e utilizam os conhecimentos e experiências adquiridas na primeira dinâmica para desenvolverem uma animação ou história que envolva a realidade de sua família ou simplesmente façam parte do imaginário da criança. Sugere-se que nesta etapa as crianças sejam as protagonistas do enredo da história e/ou animação, desenvolvendo junto de seus familiares o que elas imaginaram e idealizaram nas etapas anteriores. Para 
esta atividade as famílias tem o apoio do guia disponibilizado na etapa anterior e dos instrutores para tirar dúvidas sobre a utilização do Scratch Jr. Esta etapa tem duração de 30 minutos

Na quarta etapa, é proposto que as famílias interajam umas com as outras, escolhendo outros participantes do evento que estejam trabalhando nas proximidades, para isso, é necessário estimular que sejam feitas perguntas de interesse da família. Para auxiliar a superação desta falta de experiência, são disponibilizadas sugestões de perguntas como por exemplo: que tipos de blocos você utilizou na sua história? como vocês pensaram nesta animação? o que vocês fariam de diferente se tivessem mais tempo? de onde veio a inspiração para a criação da história?

O objetivo é que nesta etapa as famílias troquem experiências quanto as animações e/ou histórias desenvolvidas e ao mesmo tempo se conheçam mais quanto responsáveis de suas crianças, estimulando um vínculo mais pessoal entre eles. Esta etapa tem duração de 15 minutos.

Na quinta etapa é reservado 20 minutos para que as famílias possam finalizar suas criações ou realizar melhorias caso já tenham terminado. Por fim, a sexta etapa traz a proposta de que as famílias apresentem para o grupo suas criações, esta etapa não é apresentada de forma obrigatória, sendo assim somente as famílias que se sentirem confortáveis para apresentar, farão a demonstração de seus projetos e as demais serão apenas espectadores das apresentações.

Esta última etapa tem a duração aproximada de $\mathbf{2 5}$ minutos. Após as seis etapas de projeto, as famílias e os instrutores são convidados a organizarem o espaço onde o evento foi realizado. Na próxima subseção serão discutidas a infraestrutura mínima necessária para a aplicação do projeto, tal como recursos e sugestões de atividades e materiais para a realização do evento.

\subsection{Métodos e Materiais}

Para a realização da experiência sugere-se que a escola disponibilize dois ambientes diferentes para que seja possível a separação dos grupos na segunda etapa, sendo um dos ambientes capaz de comportar os dois grupos de maneira confortável.

O ambiente de criação utilizado a partir da terceira etapa necessita de 1 (um) cadeira por pessoa e 1 (um) mesa para cada duas famílias. Dependendo do número de participantes, sugere-se a utilização de 1 (um) microfone e 1 (uma) caixa de som para facilitar a comunicação da equipe organizadora com os participantes e para que na sexta etapa facilite a apresentação dos trabalhos.

A aplicação Scratch Jr pode ser executada somente em tablets com sistema operacional iOS e Android. Sugere-se que ao utilizar dispositivos com sistema operacional Android, os projetos sejam salvos sempre que possível e que os aparelhos tenham como requisitos mínimos de hardware um 1 GB de memória ram, câmera frontal e traseira e esteja utilizando a versão 4.2 ou superior do sistema operacional Android.

Para realização do evento faz-se necessário uma série de materiais distintos para cada uma das etapas do evento. Estes materiais podem ser verificados em https://goo.gl/VbBzVT . 
Por fim, o ambiente de aplicação pode ser tanto o vivenciado pelas crianças em seu cotidiano escolar, quanto outros espaços presentes na escola/centro educacional. No entanto, é importante que para as etapas de criação seja disponibilizado espaço suficiente para comportar o número total de participantes durante as atividades.

\section{Resultados Obtidos}

Com o objetivo de verificar a validade do protocolo apresentado no Capítulo 2, foram realizadas atividades de introdução a programação com crianças de 5 anos de idade, não alfabetizadas e sem experiências prévias em programação e seus familiares. As atividades ocorreram fora da sala de aula tradicional, mas ainda assim dentro do espaço escolar do Centro Educacional no qual foi aplicado. A ferramenta de programação utilizada foi o Scratch $\mathrm{Jr}$, por ser aderente a crianças nesta faixa etária e por não gerar nenhuma barreira de idiomas. A ferramenta apresenta uma notação de blocos e não exige alfabetização

Serão discutidos neste relato de experimento os principais resultados obtidos em dois dias de aplicação das atividades, que envolveram 15 famílias no primeiro dia e 19 famílias no segundo, somente uma família que esteve no primeiro dia compareceu no segundo dia. Também se envolveram nestas atividades estudantes de graduação de diferentes cursos e que atuaram como monitores nas atividades e auxiliaram em demandas que ocorreram ao longo do desenvolvimento dos projetos de cada família. A equipe de pesquisa que atuou nas atividades, deste modo, foi formada por um professor pesquisador, cinco estudantes de graduação e dois professores que já trabalham com a turma de educação infantil do Centro Educacional. Nas próximas subseções serão apresentados os resultados de aplicação do protocolo apresentado na seção 2.2, de modo a compartilhar as principais experiências obtidas em cada uma das etapas.

\subsection{Ambiente de Aplicação}

As atividades que aconteceram nos projetos citados neste relato de experiência, foram desenvolvidos em um grande pátio interno do Centro de Educação Infantil (CEI). Foi neste espaço que as atividades de codificação, compartilhamento e apresentação ocorreram. No entanto, as atividade da Etapa 2, tem como necessidade a disponibilidade de pelo menos dois ambientes distintos, pois em um primeiro momento os familiares e as crianças são direcionados para espaços diferentes para que possam vivenciar experiências diferentes.

\subsection{Público-Alvo}

Nesta atividade foram convidadas crianças de 5 anos de idade, da rede pública de ensino da cidade de Itajaí. Para participar destas atividades foi necessária a participação de pelo menos um responsável (familiar) para acompanhar a criança. Fazem parte do grupo de familiares qualquer responsável pela criança, independente de faixa etária e gênero, que tivesse por objetivo acompanhar as crianças durante todo o percurso de atividades. Os principais objetivos destas interações consistem em cativar a criança por meio de conversas sobre o tema fora do ambiente escolar e ao mesmo tempo promover a participação da família na escola em atividades que envolvam tecnologia.

\subsection{Relato das Atividades Desenvolvidas}


As atividades foram desenvolvidas, inicialmente, em dois grupos distintos, sendo eles (i) o grupo dos responsáveis pelas crianças, classificados como familiares e (ii) o grupo de crianças de 5 anos de idade. Serão relatadas neste documento, as seis etapas que constituem a aplicação do protocolo no dia do evento, deste modo, a atividade que envolveu a criação do crachá não será detalhada no escopo deste artigo.

Além disso, a primeira etapa do evento, tratou apenas da entrega dos crachás e tablets e no contexto desta pesquisa, não apresentou nenhum detalhe especial, desse modo, serão relatadas a seguir os resultados da Etapa 2 em diante.

\subsubsection{Etapa 2 - Olá Mundo}

$\mathrm{Na}$ segunda etapa, os responsáveis tiveram acesso ao uso da ferramenta Scratch $\mathrm{Jr}$, acompanhada de uma pequena formação sobre como ela funciona e esclarecendo alguns aspectos como animação e programação, definições de ator, fantasia, sequência, direções, posicionamento em tela e áudio. Para esta etapa foi realizada a tradução de um guia disponibilizado pela universidade que desenvolve e mantém a ferramenta Scratch Jr. Este documento permitiu que os familiares tivessem um material de apoio para que pudessem superar algumas das dificuldades encontradas ao longo do desenvolvimento do projeto.

Em um primeiro momento, durante 20 minutos, os familiares participaram de uma atividade expositiva, onde foram engajados a acompanhar todos os elementos apresentados no guia. $\mathrm{Na}$ etapa seguinte, durante 10 minutos, foram sugeridas práticas de exploração livre da ferramenta para que pudessem investigar conceitos que fossem de seu próprio interesse.

Foi possível perceber que a maioria dos responsáveis, mesmo aqueles com idade acima dos 60 anos, já tinham alguma familiaridade com a interface de toque de tela, o que facilitou muito a interação com o aplicativo. Aos que não demonstravam uma maior intimidade com a tecnologia, não foi necessário muito tempo de dedicação para que começassem a se acostumar com o funcionamento da aplicação.

O aplicativo não gerou nenhuma dificuldade de uso por parte dos pais/responsáveis nesta etapa de introdução, acredita-se que o guia tenha auxiliado de alguma forma nesta etapa e que o fato da linguagem de programação ser por meio de blocos de programação e não com uma sintaxe textual tradicional, a facilidade em compreender as ações aconteceu de forma mais intuitiva e natural. Enquanto era feita a demonstração de funcionalidades básicas, alguns familiares já demonstravam interesse em ações mais complexas, como a possibilidade de mudança de tamanho de personagem e até mesmo de conceitos mais abstratos como loops, mesmo que não por este nome. Comprovando desta forma, que o Scratch Jr. permite que pessoas que nunca interagiram com linguagens de programação podem criar seus primeiros programas com uma abordagem de blocos simplificados.

Em paralelo a esta atividade, foi também desenvolvida uma atividade com as crianças com a intenção de familiarizá-los com os personagens do ScratchJr (ver Figura 2), além, de estimular a criatividade na pintura e criação de histórias para cada personagem apresentado.

Neste processo foi possível perceber que as crianças possuem muita criatividade 
e isso pode ser explorado de forma mais contínua pelos professores, porém, muitas vezes essa criatividade é abordada de forma rígida pelo educador que acaba limitando o pensamento dos alunos. Ainda nesta etapa, as crianças foram estimuladas a pensar em histórias, criar seus cenários e colorir personagens que fazem partem do mundo do Scratch Jr, conforme a Figura 2.

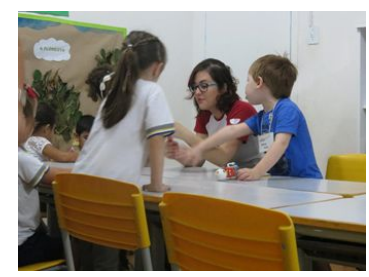

Figura 2. Crianças conversando sobre suas histórias

É importante frisar que nesta fase a presença de pelo menos um educador e dois pesquisadores com conhecimento na ferramenta é fundamental, pois as atividades envolvem demonstrações de animações com o Scratch Jr que sejam capaz de ilustrar movimentos que a aplicação permite realizar e para conversar com cada grupo de crianças sobre o que gostariam de fazer na próxima etapa com seus pais.

\subsubsection{Etapa 3 - Criando}

$\mathrm{Na}$ terceira etapa, ao juntar novamente os familiares com as crianças no mesmo ambiente, pode-se perceber um comportamento inesperado por parte dos adultos que trouxe algumas reflexões à equipe de pesquisadores. Os estudantes, que haviam acabado de passar por uma atividade cuja intenção era aguçar a criatividade, acabaram por vezes tendo suas ideias para a história criticadas pelos adultos por não serem coerentes com a realidade, critério este que não foi indicado em nenhum momento pela equipe que aplicou as atividades, que inclusive de modo contrário, aconselhou os responsáveis durante o treinamento da ferramenta a serem criativos. Talvez até por não estarem habituados a ver a capacidade de criar de seus filhos é que os pais/responsáveis fizeram essas intervenções, não justifica porém como foi um primeiro momento de participação com seus filhos, imagino que até os mesmos se surpreendem com tal capacidade, vale ressaltar que quando os pequenos têm oportunidade nos mostram o quanto são capazes de aprender e criar usando a imaginação.

Esta reflexão permite sugerir, que em aplicações futuras deva-se dedicar um tempo na etapa em que os adultos estão separados das crianças, para destacar de forma mais acentuada que o projeto não tem restrições quanto a forma, coerência ou representação, desde que contemple uma decisão comum entre os adultos e as crianças. Os familiares e crianças não demonstraram dificuldades na etapa de criação, o que dá indícios de que a formação inicial para os responsáveis tenha sido eficiente quanto ao preparo para o uso da ferramenta. A Figura 3, por exemplo, apresenta alguns familiares e suas crianças durante a etapa de criação de suas histórias e animações.
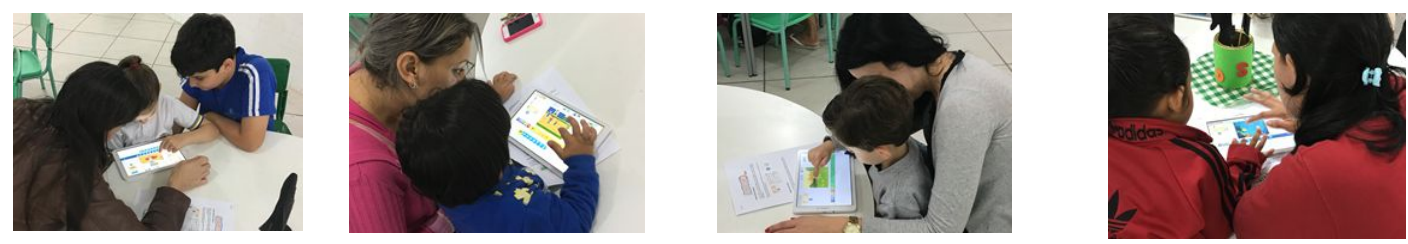
Figura 3. Familiares e crianças nas etapas de criação

Foi possível perceber que a acústica do ambiente onde a atividade influencia em como serão os projetos, pois em ambientes com a acústica prejudicada ou onde existe muito barulho não é cabível a utilização da gravação de áudio para as histórias desenvolvidas pelas famílias, e isto pode, de certa forma acabar limitando o uso de recursos nas animações. Durante toda a etapa de criação alguns tablets de menor desempenho apresentaram problemas para captura de áudio, customização de fantasias e fechamento da aplicação. Sugere-se que os que não apresentarem as características mínimas citadas na seção de materiais, sejam frequentemente estimulados a salvarem suas histórias.

De modo geral, esta é a etapa onde a família mais se diverte, é possível ver a interação entre os conhecimentos que foram passados para os pais sobre a ferramenta e a criatividade das crianças, também instigada na primeira etapa, e passando pelas mesas foi possível notar que durante a criação das histórias houve uma grande sinergia na integração, criação e codificação.

\subsubsection{Etapa 4 e 5 - Compartilhamento e Ajuste dos Projetos}

A quarta etapa tem como função o compartilhamento das histórias, a integração proposta por essa etapa visa uma maior aproximação da comunidade escolar, visto que por ser feita em pequenos grupos, permite não só o compartilhamento de questões relacionadas à atividade, como dificuldades com a ferramenta, abordagens de criação e experiências, como também permite que os responsáveis se conheçam melhor (ver Figura 4).

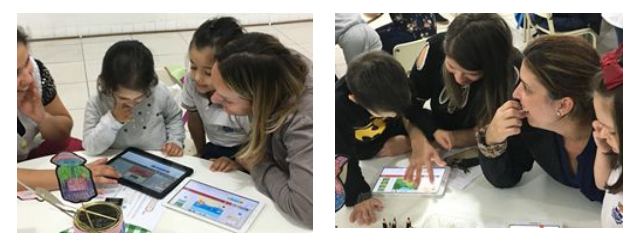

Figura 4. Compartilhamento de projetos entre as famílias

A maioria das famílias teve facilidade nesta etapa, e inclusive algumas fizeram modificações em seus projetos à partir de ideias geradas pelo compartilhamento dos projetos. Uma minoria entretanto, teve dificuldade em se relacionar com as outras famílias, acredita-se que isto ocorre devido a características, como timidez e insegurança das próprias crianças e responsáveis. Nesta etapa muitos dos responsáveis se conheceram pela primeira vez e puderam compartilhar suas experiências com através do uso da ferramenta.

\subsubsection{Sexta Etapa - Apresentação dos Projetos}

A satisfação dos responsáveis e orgulho dos estudantes é a principal característica desta etapa. As famílias compartilham com todos as suas histórias, conforme observado na Figura 5, assim que a proposta foi dada, muitos não se sentiram à vontade com a ideia de apresentar para todos. Após a primeira família apresentar o seu projeto entretanto, este clima desapareceu, e todos se sentiram bem mais confortáveis, e 
assim as famílias foram se apresentado sucessivamente.
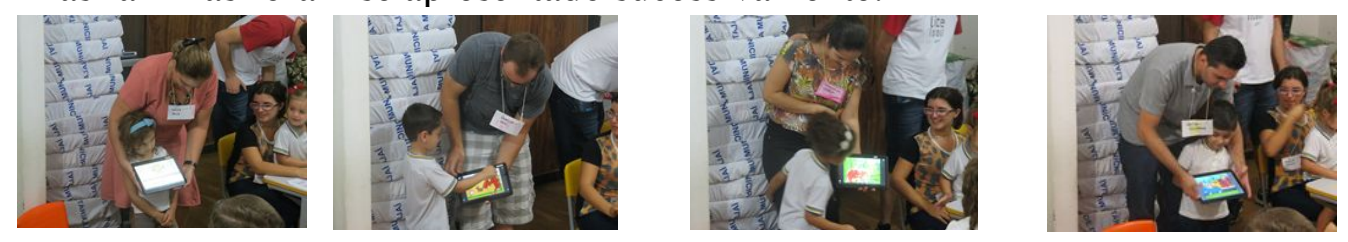

Figura 5. Apresentação dos projetos desenvolvidos

Com um ambiente simples, e a ajuda de um microfone, as famílias apresentaram seus projetos de maneira bastante informal, normalmente sendo as crianças a falarem ao microfone, o que promoveu um ambiente interativo e descontraído. Para a equipe de aplicação, esta tenha talvez sido a etapa onde mais se pode perceber a diferença gerada pela atividade no comportamento das famílias, não só pela integração como também pelo relacionamento dos responsáveis e estudantes com as tecnologias.

Os projetos eram variados e demonstravam como cada família pode ter uma experiência própria com a ferramenta e a atividade. Em muitos momentos foi possível perceber o quanto os estudantes conseguiram fazer os pais serem criativos e pensarem 'fora da caixa'.

\section{Conclusões}

Em Scratch Jr: brincando em família, professores, educadores, pais/responsáveis e crianças da comunidade do CEI Prof Rosana Aparecida de Souza tiveram um dia com atividades diferentes, que foi possibilitado por meio de atividades relacionadas a programação, criação e apresentação de histórias, em que as crianças e seus responsáveis assumiram o papel de autores de suas obras.

Nas etapas iniciais do evento, foi possível perceber a dedicação dos pais/responsáveis em compreender como a tecnologia funcionava e quais eram os conhecimentos necessários para auxiliar as crianças durante as próximas etapas. $\mathrm{O}$ mesmo ocorreu com as crianças, que estavam o tempo todo entusiasmadas por receber sua família na escola, em um dia atípico. As crianças se sentiram motivadas ao perceber que poderiam criar histórias animadas e ao utilizarem os tablets durante o período escolar, no entanto, pode-se afirmar que as atividades mão-na-massa como pintura e criação dos crachás também foi um aspecto muito importante para o evento.

O grande desafio em apresentar programação para as crianças não está relacionada a complexidade da ferramenta, mas sim, em caracterizar bem a proposta que deseja ser trabalhada, estabelecer uma boa conexão com o espaço escolar e viabilizar a compreensão de todos os envolvidos que o principal ganho do processo está estimular a criatividade das crianças e, no contexto desta pesquisa, permitir que os pais/responsáveis façam parte deste protagonismo.

Por ser novidade, o evento causou impacto tanto nos familiares, quanto nos educadores dos Centro Educação Infantil. As crianças demonstraram o quanto são capazes e ficaram encantados em manusear um tablet para criação de jogos e história, fazendo com que a imaginação de cada um fosse além das expectativas dos adultos. Tal encantamento pode ser observado por cada detalhe, no momento em que se apresentou o que foi criado, podendo ser observado que a ferramenta foi utilizada realmente para 
VI Congresso Brasileiro de Informática na Educação (CBIE 2017)

Anais do XXIII Workshop de Informática na Escola (WIE 2017)

desenvolver a criatividade.

O protocolo disponibilizado pela Universidade de Tufts permitiu executar um evento piloto que antecedeu o relato nesta proposta. Os resultados desta primeira interação permitiram verificar que para realidade brasileira, é necessário um tempo maior de contato com a proposta envolvida na temática do Scratch Jr, sugerindo assim, (i) um encontro prévio com a comunidade de educadores da escola; (ii) atividades mão-na-massa com as crianças e que sejam valorizadas no dia do evento; (iii) conversas com os adultos e crianças, com o objetivo de fortalecer o imaginário infantil; (iv) promover uma integração entre as famílias já nas primeiras dinâmicas de uso do tablet (na etapa em que os adultos estão separados) e principalmente (v) uma etapa em que a criança seja estimulada a pensar em sua história e como os personagens serão construídos.

Como legado do evento para a cidade, o Scratch Jr: brincando em família afetará mais escolas até o final de 2017 e espera-se que este documento viabilize que outras regiões do país possam realizar atividades semelhantes.

\section{Aspectos Éticos}

Todas as crianças e professores retratados neste artigo autorizaram por escrito previamente o uso das imagens para fins de divulgação científica do projeto.

\section{Referências}

FLANNERY, Louise P. et al. Designing ScratchJr: Support for early childhood learning through computer programming. In: Proceedings of the 12th International Conference on Interaction Design and Children. ACM, 2013. p. 1-10.

RAABE, A. L. A; SANTANA, A. L. M; RODRIGUES, A. J; VIEIRA, M. V; ROSÁRIO, T; CARNEIRO, A. C. R. Brinquedos de Programar na Educação Infantil: Um estudo de Caso. Brinquedos de Programar na Educação Infantil: Um estudo de Caso. In: Anais do Workshop de Informática na Escola. 2015. p. 42.

PAPADAKIS, Stamatios; KALOGIANNAKIS, Michail; ZARANIS, Nicholas. Developing fundamental programming concepts and computational thinking with ScratchJr in preschool education: a case study. International Journal of Mobile Learning and Organisation, v. 10, n. 3, p. 187-202, 2016.

PORTELANCE, Dylan J.; STRAWHACKER, Amanda L.; BERS, Marina Umaschi. Constructing the ScratchJr programming language in the early childhood classroom. International Journal of Technology and Design Education, v. 29, n. 4, p. 1-16, 2015.

PORTELANCE, Dylan J.; BERS, Marina Umaschi. Code and Tell: Assessing young children's learning of computational thinking using peer video interviews with ScratchJr. In: Proceedings of the 14th International Conference on Interaction Design and Children. ACM, 2015. p. 271-274.

RESNICK, Mitchel. All I really need to know (about creative thinking) I learned (by studying how children learn) in kindergarten. In: Proceedings of the 6th ACM SIGCHI conference on Creativity \& cognition. ACM, 2007. p. 1-6.

STRAWHACKER, Amanda et al. ScratchJr Demo: A coding language for Kindergarten. In: Proceedings of the 14th International Conference on Interaction Design and Children. ACM, 2015. p. 414-417.

TEIXEIRA, Adriano et al. Programação de computadores para alunos do ensino fundamental: A Escola de Hackers. In: Anais do Workshop de Informática na Escola. 2015. p. 112. 